\title{
Бизнес и нравственность: противоречие или сопутствие
}

\author{
прот. Ростислав Ярема \\ badacz niezależny \\ Moskwa, Rosja \\ prot.rostislav@gmail.com
}

rev. Rostislav Yarema, Business and morality: contradiction or concomitant, Elpis, 19 2017: 201-206.

ks. Rostislav Yarema, Biznes i moralność: sprzeczność czy wspótbrzmienie, Elpis, 19 2017: 201-206.

\begin{abstract}
The article raises the problem concerning mechanisms of the interrelation of modern business in Russia and morality, also it raises the issue of dialectical, diachronic correlation of these concepts or consideration of their synchronous interaction, oriented to the general welfare of society. In the course of the problem's analysis, examples of entrepreneurial activity of industrialists and philanthropists of the early 19th-20th centuries are given, the role of Orthodox values and the national traditions formed on their basis in the course of regulating these mechanisms are examined.
\end{abstract}

\begin{abstract}
Аннотация: В статье поднимается проблема действия механизмов взаимосвязи современного бизнеса в России и нравственности, поднимается вопрос диалектического, диахронного соотношения этих понятий или рассмотрения синхронного их взаимодействия, ориентированного на общее благосостояние общества. В ходе анализа проблемы приведены примеры предпринимательской деятельности промышленников и благотворителей рубежного времени XIX - XX вв., рассмотрена роль православных ценностей и сформированных на их основе национальных традиций в ходе регулирования указанных механизмов.

Streszczenie: Autor podejmuje problem funkcjonowania mechanizmów współzależności między współczesnym biznesem w Rosji a moralnością, podejmuje kwestię dialektycznej, diachronicznej korelacji tych pojęć bądź też próbę rozpatrzenia synchronicznego ich współdziałania zorientowanego na ogólny dobrobyt społeczeństwa. W toku analizy problemu autor prezentuje przykłady z działalności przedsiębiorczej przemysłowców i filantropów przełomu XIX-XX ww., rozpatruje rolę prawosławnych wartości i ukształtowanych na ich gruncie tradycji narodowych w toku kształtowania się wymienionych mechanizmów.
\end{abstract}

Keywords: moral business, thirst for enrichment, goal-setting of entrepreneurial activity, social responsibility, entrepreneurs of the late XIX - early XX centuries, Orthodox values

Ключевые слова: нравственный бизнес, жажда обогащения, целеполагание предпринимательской деятельности, социальная ответственность, предприниматели к. XIX - нач. XX вв., православные ценности

Słowa kluczowe: moralny biznes, żądza bogacenia się, stawianie celów w biznesie, odpowiedzialność społeczna, przedsiębiorcy końca XIX - początku XX ww., wartości prawosławne

Проблема «бизнес и нравственность» имеет давнюю историю, источником которой стала жажда наживы. Еще Платон определял стремление к богатству причиной всех несправедливостей и пороков, как страсть, не имеющую пределов. («Государство»). Однако стоит ли, подчиняясь современной тенденции сводить понятие бизнеса только лишь к стремлению к обогащению.

Главной иллюзией предпринимательского сообщества стало то, что рынок не нуждается в каких-либо нравственных ограничениях и своей «невидимой рукой» (А. Смит) сам отрегулирует результаты своей деятельности и направит их на благо общества. Потому и хозяйская деятельность - сама по себе, а нравственность - сама по себе. А осуществление рыночных целей само по себе приводит к общему благу ${ }^{1}$. Дорого

\footnotetext{
См: Смит А. Исследование о природе и причинах богатства народов» (1776 г.)
}

человечество заплатило - и до сих пор платит - за эту разрушительную иллюзию.

Просветители пытались снять очевидное противоречие теорией разумного эгоизма, утверждавшей, что реализация собственных интересов может не только не противоречить интересам общественным, но и быть им полезной. Но здесь вполне возможный частный случай выдавался за универсальное и, якобы, автоматически действующее правило, которое в жизни легко опровергалось. Известное положение о том, что капитал при $100 \%$ прибыли попирает все человеческие законы, а при 300\% готов пойти на любое преступление, лучше всего показывает, что одна иллюзия сменила другую. В XX веке эта откровенность сняла флер с подлинного лица бизнеса устами Милтона Фридмана, который прямо указал, что максимальная прибыль - основная функция бизнеса и все остальные, в том числе ответ- 
ственность перед обществом, - от этого только отвлекают ${ }^{2} \ldots$

Практически эти и все последующие «теории» презумпции этической невиновности бизнеса были попытками его самооправдания и изоляции от общественной ответственности и не выходили за рамки идеологии и психологии предпринимательского сообщества. Суть их сводилась к стремлению разделить бизнес и нравственность, освободить предпринимателя раз и навсегда от каких либо нравственных норм. Возможно поэтому проблема «бизнес и нравственность» чрезвычайно актуализировалась в наше время.

Острая критика бизнеса за ненасытную жажду наживы уже со второй половины XX века породила антилиберальные настроения и обрела новую силу на волне неприятия глобализации и обвинений транснациональных предприятий в усилении раскола между богатыми и бедными, снижении социальных стандартов и создании в развивающихся странах рабских условий труда, в том числе детского, загрязнении окружающей среды и искусственном сдерживании в этих странах социального прогресса (особенно в образовании и медобслуживании населения), в торможении процесса модернизации стран, где размещаются предприятия транснациональных компаний.

Результаты все убыстряющегося благодаря бизнесу развития индустрии, ориентированной на потребительское сообщество, подвели человечество к экологической и гуманитарной катастрофе: продукты ГМО, загрязненные воздух и вода и т.д. А если добавить к этому эскалацию военных конфликтов и расширение гуманитарных кризисов, за которыми всегда стоит чей-то экономический интерес, то масштабы проблемы становятся практически непреодолимыми. Асоциальный и аморальный характер установки производство ради прибыли - предполагает реакцию безудержного потребительства, подменяющего у миллионов людей смысл человеческого существования с цели быть на цель иметь (Э. Фромм). Это вторжение в нравственную структуру общества, подмена прежнего типа культуры и морали, основанных на непреходящих ценностях человеческого бытия. Именно такую - если смотреть в корень - попытку и предпринимает бизнес, пытаясь высвободиться от каких бы то ни было нравственных требований, канонов и обязательств по отношению к обществу, от общепринятой морали. Поэтому многие ученые вынуждены согласиться с достаточно печальным выводом о том, что на данном этапе «культура и экономика разошлись в своем развитии» (П. Козловски).

Тем ни менее здравый анализ ситуации со стороны научного сообщества порождает противодействие такому типу бизнеса. Возникли понятия социальной ответственности бизнеса, появились понятия экологической культуры и экологии культуры, которые применяются в формировании у людей нравственных

\footnotetext{
См.: Фридмен М. Капитализм и свобода. 1962 г.
}

установок к соблюдению общих интересов общества, береженому и охранительному отношению к природе, а также в понимании столь же бережного и охранительного отношения к выработанным человечеством ценностям культуры духовной и материальной. Все чаще стала подниматься проблема смены приоритетов, сопровождающихся разрушительными тенденциями на приоритеты, имеющие созидательную суть.

Недопустимость противопоставления потребностей экономики и человеческой справедливости признают не только обычные люди, но и представители вполне научного направления исследований - экономической этики ${ }^{3}$. Да и сами представители деловой элиты время от времени говорят об «общих ценностях» ${ }^{4}$, о «благородном бизнесе».

Вся сложность проблемы взаимоотношений бизнеса и нравственности состоит в определении механизмов их взаимосвязи. Чаще всего два понятия противопоставляют друг другу и об их сближении говорят лишь в диалектическом смысле, как возможном единстве двух противоположностей.

С учетом понимания бизнеса, как стремления к обогащению достаточно трудно совместить два многомерных понятия, включающих порой противоположные смыслы и типы деятельности - и бизнес, и нравственность по природе своей становятся слишком сложны и многозначны.

Проблему пытаются решить в диахронической плоскости - то есть обсуждать возможности сближения и согласования этих разновекторных типов деятельности и систем ценностей. Но не является ли еще одной современной иллюзией сама возможность соединить противоположные системы ценностей: наживы на человеческих страстях и благодеяния на пользу общества? Несомненно, компромиссам на пути такого сближения будут способствовать определенные попущения, идущие в разрез с понятиями нравственными.

Возможно для решения проблемы и изменения действия предпринимательских механизмов, стоит исходить из синхронного рассмотрения понятий бизнеса и нравственности, исключить их диалектическое понимание и попытаться сформулировать понятие «экологии бизнеса». Современные бизнес технологии должны строиться, не исходя из противопоставления указанных понятий, а из их внутренней взаимосвязи, где частное благо - есть часть блага общего, где реализация идеи частного, рождает ответную благодарность.

Нравственным или безнравственным бизнес делает целеполагание, формирующееся в личном пространстве предпринимателя. Именно здесь начинается распад бизнеса и нравственности, здесь расходятся вектора нравственного и безнравственного бизнеса. Бизнес или вписывается в общепринятую моральную парадигму или вырабатывает особую систему нрав-

3 В частности, А. Рих в своей двухтомной «Хозяйственной этике» (1984, 1990).

4 Например, теория «общих ценностей» М. Портера и М. Креймера. 
ственности. Противоречие между общечеловеческой нравственностью и нравственностью бизнеса составляет в этом случае проблему. «Успех любой ценой для нас неприемлем. Эта цена не стоит утраты человеческого достоинства, разрушения совести, отказа от внутренней гармонии с самим собой и с окружающим. Свобода в нашей стране не может быть выше нравственности», - говорит депутат Государственной Думы России Виктор Зубарев ${ }^{5}$.

Прежде всего, необходимо определиться в терминах. Бизнес сам по себе - это не только социальный институт, но и одна из технологий социальной деятельности, обеспечивающая функционирование и развитие общества, удовлетворение потребностей граждан. Бизнес определяется внешними условиями - потребностями общества в конкретном продукте и возможностями его создания в существующей юридической и экономической реальности. Конечно же, он во многом зависит и от личности предпринимателя. Очевидно, то благо, которое приносит предпринимательская деятельность людям, обеспечивая их физическое существование и функционирование общественно-экономической системы в целом. Невозможно отрицать ни значимость его для общества в целом, ни для самого предпринимателя. Чем выше уровень дохода, тем больше возможности развития созидательного потенциала и самореализации человека - в социальной практике, в духовно-творческой деятельности.

Бизнес доказал свою общественную и экономическую эффективность, обеспечивая развитие общества и функционирование социальных институтов. Уже это вполне оправдывает существование этого социального института и предпринимательской деятельности как таковой. Спор идет только о цели, в формировании которой приоритет отдается личной корысти или общественному благу. Определить, нравственный ли бизнес можно только по одному критерию: что из этих двух ипостасей бизнеса является целью, а что средством. «Не прибыль портит людей, а люди портят прибыль», говорил Преподобный Амвросий Оптинский.

Осуждать бизнес как «безнравственную деятельность» в принципе не верно - точно так же, как любой другой социальный институт, деятельность которого может приводить к взаимоисключающим результатам. Само по себе рыночное хозяйство как социальный механизм производства и распределения, обеспечивающий получение общественных благ и повышение жизненного уровня, не может быть аморальным. Множество примеров говорят, что бизнес-механизм продуктивен в поле нравственности и социального блага, и не только потому, что благодаря этому обеспечивает себе стратегический долгосрочный эффект. Он еще даёт человеку - то, без чего не может сложиться его счастливая жизнь, - спокойную совесть и сознание собственного достоинства, другими не оспоримого. Вот почему, «...когда мы говорим о предприниматель-

\footnotetext{
Элита России. Журнал людей успеха. 2008, март, С. 14.
}

стве, то в первую очередь следует сказать, что предприниматель должен быть нравственным человеком. Безнравственный предприниматель так же страшен, как безнравственный врач или учитель», - считал архиепископ Евгений Верейский.

Социальная ответственность бизнеса трактуется по-разному: сторонники популярной на Западе «теории корпорации» отметают какие-либо общественные обязательства от главной и, как они считают, единственной цели бизнеса - прибыли. Этой точке зрения сторонники «теории метрокорпорации» противопоставляют мнение о необходимости служения общественному благу ${ }^{6}$. Реальность бизнеса свидетельствует о балансировании между этими двумя крайностями. Но обществу требуются гарантии того, что его интересы не будут зависеть от доброй воли или характера воспитания бизнесмена - он должен действовать в рамках правового поля и в той нравственной парадигме, которая в обществе сложилась. Конечно, бизнес требует и государственного правового регулирования экономики, заключая в определенные рамки общепринятой морали стремление к выгоде, позволяя соблюсти интересы личные и общественные.

Нравственность - понятие внеэкономическое, но оно обладает огромной силой воздействия на все сферы общественной жизни, в том числе экономику. Существуют разные трактовки нравственности - одни возводят ее к началу божественному, как источнику и воплощению нравственных ценностей, другие связывают с самим человеком, сумевшим в борьбе за существование выработать систему ценностей, затем определенных правил (морали). К сожалению, знаменитого аристотелевского определения этики как знания того, что следует делать и от чего следует воздержаться в нынешней реальности не достаточно. Знание о недопустимости безнравственного поступка далеко не всегда останавливает человека. Перейти границу может помешать только совесть и воля не делать последнего невозвратного шага.

Вряд ли можно признать бесспорным утвердившееся представление о несовместимости религиозных ценностей, составляющих основу и суть нравственности, со свободой индивидуального самовыражения ${ }^{7}$, одной из форм которого является предпринимательство. Православные ценности вполне могут выступать регуляторами немеркантильного поведения людей и в XXI веке. Например, доверие, которое, как считает Ф. Фукуяма ${ }^{8}$, обеспечит сотрудничество внутри общества и добродетельность предпринимателя.

Применительно к теме статьи национальная традиция, основанная на православной этике, утверждает, что материальное богатство - само по себе не благо-

\footnotetext{
Браим И. Этика делового общения. - Минск, 1996. С. 20-21.

Инглегарт Р. Культурный сдвиг в зрелом индустриальном обществе // Новая индустриальная волна на Западе. Антология , Под редакцией В.Л. Иноземцева. - М.: Academia, 1999. - С. 255.

8 См.: Фукуяма Ф. Доверие: социальные добродетели и путь к процветанию: (пер. с англ.). - М.: АСТ Москва: Хранитель, 2006.
} 
словение и не наказание. Это, прежде всего, испытание и ответственность. Дело - настоящее, захватывающее человека целиком,- вот главное богатство и главный внутренний стимул нравственного предпринимателя. Отсутствие культа денег раскрепощает его, делает его внутренне свободным и несказанно обогащает его внутренний мир. Для нравственного человека собственность есть не только средство извлечения выгоды, но и средство служения идеалам добра и справедливости. Собственность даёт максимальную отдачу именно тогда, когда она употребляется эффективно, а плоды её использования распределяются справедливо и ответственно, «вкладываются» в социальную стабильность. Если же человек создает материальные блага исключительно для себя, своей семьи, своей социальной группы, при этом пренебрегая интересами всего общества в целом,- он не только преступает нравственный закон, но и многое теряет в экономическом смысле. Благосостояние добросовестных предпринимателей и тружеников должно соответствовать их трудовому вкладу, быть следствием создания, рачительного использования и приумножения ими общественно полезных благ.

Стоит ли в таком случае соглашаться со мнением о том, что «нравственный бизнес есть фикция или идеологемма, созданная методом гипостазирования для достижения определенных идеологических целей. В частности, для придания «человеческого лица» нынешнему российскому бизнесу, одержимому стремлением к извлечению прибыли любой ценой, игнорируя какие-либо нравственные скрепы»? ${ }^{9}$ Естественно, стоит прислушаться к такой оценке современного российского ученого - хотя бы для того, что нужно меня в экономике, в бизнесе, в политике.

Нравственный бизнес - это предпринимательское творчество, в основе которого лежит огромный труд и внутреннее сознание ответственности за его результаты. Сама по себе собственность не замыкает пространство вокруг человека в соответствии с цифрами, которым оно эквивалентно. Оно многократно увеличивает потенциал самореализации личности, дает возможность выйти за рамки самого себя, изменить мир и жизнь окружающих.

Каким образом эти общие положения о бизнесе и оценки его нравственной ипостаси эксплицируются на Россию? Национально-конфессиональная специфика любой страны, конечно же, особенности экономического склада и предпринимательства проявляют себя в любой сфере, но лишь подтверждая общие правила и сущностные характеристики такого важнейшего социального институт современного общества, как бизнес и его взаимосвязь с нравственным климатом в той или иной стране.

Примеров, убеждающих лучше общих посылов и абстрактных положений, предостаточно. Можно

\footnotetext{
9 Тюленев А.И. Нравственный бизнес как проблема социологической науки и социальной практики. - Вестник экономики, права и социологии, 2015, №1, С.232.
}

вспомнить российских благотворителей конца XIX начала XX вв.

«Правильное распоряжение богатством всегда считалось на Руси искусством и даром Божьим», - определил эту специфику Патриарх Всея Руси Кирилл, в своем выступлении еще в качестве митрополита на 11 Всемирной русском народном соборе. Объясняется это тем, что исторически российская духовно-нравственная традиция по преимуществу склонялась к приоритету духовного над материальным, к идеалу самоотвержения личности ради блага народа. Приоритет духовного над материальным, обшей пользы над частным интересом, $М Ы$ над $Я$ стал генотипом нашей культуры, одним из отправных, основополагающих смыслов существования не только отдельного человека, но и всей нашей цивилизации. Даже если действительность вынуждает поступать наоборот, это остаётся внутренним мерилом содеянного и не даёт успокоиться совести. Такая специфика определяет характер деятельности человека и общества во всём - от экономики и политики до отношений с соседями и близкими.

Национальный характер и особенности менталитета россиян во многом определили и характер деятельности отечественного предпринимательства с момента его зарождения до нынешних дней. В России испокон веков существовал свой, воспитанный православием идеал хозяйствования: «Богатство - перед Богом грех, а бедность - перед людьми», «Кормит не богатый, а тороватый», то есть щедрый, крепкий хозяин, достаток которого позволяет достойно содержать семью и участвовать в жизни общины, жертвовать на храм и благотворительность, помогать бедным. «Тороватость» воспринималась как благо, в отличие от богатства. В православной парадигме богатство не благословенно кроме того, которое употреблено на благо людям, только оно праведное.

Русские предприниматели считали доход даром Божьим и не складывали его в иностранных банках, а пускали во благо общества. Не случайно одним из принципов этической традиции российского предпринимательства было: «Прибыль выше всего, но честь превыше прибыли». Деловая репутация - это долгосрочный актив. Она долго зарабатывается, но легко теряется. Более ста лет назад Петр Третьяков, человек исключительной культуры, ума и богатства, говорил: «Мое слово тверже документа».

Еще в 1912 году российским деловым сообществом были опубликованы «Семь принципов ведения дел в России»: уважай власть; будь честен и правдив; уважай право частной собственности; люби и уважай человека; будь верен своему слову; живи по средствам; будь иелеустремлен. На VIII Всемирном Русском Народном Соборе 3 февраля 2004 года был принят «Свод нравственных принципов и правил в хозяйствовании» ${ }^{10}$.

10 1. Не забывая о хлебе насущном, нужно помнить о духовном смысле жизни. Не забывая о личном благе, нужно заботиться о бла- 
Православная церковь осуждала дачу денег взаем для извлечения прибыли, но приветствовала предпринимательство, направленное на развитие промышленности, ремесел, сельского хозяйства. Православная нравственность была нормой поведения для многих представителей предпринимательского класса - Рябушинских, Прохоровых, Щукиных и многих других купцов и промышленников России. Особенно поразителен пример Бахрушиных. Примечательно, что восемь представителей династии Бахрушиных в разное время были гласными Московской городской думы, а братья Александр Алексеевич и Василий Алексеевич в 1900 году были удостоены звания почетных граждан города Москвы. За 50 лет существования этого звания (с 1866 по 1917 г.), его получили всего 12 человек, из них от купечества - только трое: П.М. Третьяков и братья А.А. и В.А. Бахрушины.

Русские промышленники и купцы занимались созидательным трудом, они создавали новые производства, новые рабочие места. Никто из них не занимался хищнической эксплуатацией Богом дарованных нам природных богатств. Заработанные деньги они пускали на расширение производства, на освоение новых отраслей, на обновление и реконструкцию уже существовавших заводов и фабрик. Наши деды и прадеды не знали такого понятия как «отток капитала», потому что сами тогдашние «буржуа» были русские люди, предки и потомки которых были неотделимы от родной земли. Все Бахрушины захоронены либо на Даниловском кладбище в городе Москве, либо при храмах, построенных ими.

Российское государство никогда не конфликтовало с тогдашней торговопромышленной элитой государства. Состоятельные люди тех лет добровольно, по велению души, отдавали часть своего дохода обществу в виде благотворительности. Нельзя сказать, что нынешние бизнесмены совсем не жертвуют часть своих доходов, но сам характер такой «жертвенности» иной, подчас противоположный православному пониманию этого явления. Теперешние спонсоры или меценаты зачастую рассматривают благотворительность как часть своей рекламной компании.

ге ближнего, благе общества и Отчизны. II. Богатство - не самоцель. Оно должно служить созиданию достойной жизни человека и народа. III. Культура деловых отношений, верность данному слову помогает стать лучше и человеку, и экономике. IV. Человек - не «постоянно работающий механизм». Ему нужно время для отдыха, духовной жизни, творческого развития. V. Государство, общество, бизнес должны вместе заботиться о достойной жизни тружеников, а тем более о тех, кто не может заработать себе на хлеб. Хозяйствование - это социально ответственный вид деятельности. VI. Работа не должна убивать и калечить человека. VII. Политическая власть и власть экономическая должны быть разделены. Участие бизнеса в политике, его воздействие на общественное мнение может быть только прозрачным и открытым. VIII. Присваивая чужое имущество, пренебрегая имуществом общим, не воздавая работнику за труд, обманывая партнера, человек преступает нравственный закон, вредит обществу и себе. IX. В конкурентной борьбе нельзя употреблять ложь и оскорбления, эксплуатировать порок и инстинкты. Х. Нужно уважать институт собственности, право владеть и распоряжаться имуществом. Безнравственно завидовать благополучию ближнего, посягать на его собственность.
К примеру, если до революции Савва Морозов заботился о том, как обустроить досуг своих рабочих, и в ОреховоЗуеве создал одну из первых в России футбольных команд и построил отличный стадион, то ныне один из самых крупных российских олигархов, наоборот, на русские деньги купил английский футбольный клуб и за большие деньги нанимает игроков для развлечения английской публики.

Объяснение такой резкой трансформации отечественного бизнеса нужно искать не столько в 70-летнем периоде советской истории, прервавшем развития отечественного предпринимательства, и физически вырезавшем предпринимательское сословие, но и в 90-х годах прошлого века, когда заново формировался класс собственников России. Почти мгновенный перепад двух эпох и цивилизаций, которые пережила страна в «лихие 90-е», позволил заполнить предпринимательский вакуум людям, большинство которых по своим нравственным качествам ничего общего с такими людьми, как Третьяков и Бахрушины, не имели. Политическая практика создания класса собственников немедленно и любой ценой, психология быстрого обогащения вывели на авансцену истории определенный тип людей - социально активных, но далеких и от отечественных традиций предпринимательской деятельности, и от моральных устоев национального характера и российского менталитета.

Резкий переход к рынку осуществлялся по западным лекалам с полным игнорирование социокультурной и духовно-нравственной специфики России. Вполне естественно, что в общественном сознании после реформ 90-х годов утвердилось мнение, что «богатство - дело наживное, а не заработанное», что «хочешь жить богато - не будешь спать спокойно», что «бизнес и совесть - понятия обратно пропорциональные. И даже сегодня с образом предпринимателя в мнении большинства понятия чести, совести, высоконравственного поведения ассоциируются редко.

Первый и главный признак неблагополучного развития бизнеса - расширение пропасти между бедными и богатыми. Прямым наследием того времени стала коррупция, всепроникающий характер которой свидетельствуют о серьезной болезни политико-экономических структур новой России. Свидетельством неблагополучия экономики является не прекращающийся отток капитала.

Известно, что один из самых крупных отечественных экономистов, академик Дмитрий Семенович Львов назвал всю современную экономику "неправедной", предлагая ориентироваться на нравственную экономику, основанную на православных ценностях.

Представители такой научной дисциплины как этика бизнеса (в частности, Ульрих Бек, Майкл Портер, Марк Креймер) считают необходимым поставить благополучие предприятий в прямую зависимость от прогресса общества, повышения социальных стандартов населения. А. Рих в двухтомной «Хозяйственной этике» $(1984,1990)$ заявляет о недопустимости проти- 
вопоставления потребностей экономики и человеческой справедливости.

Сложность заключается в реализации подобных идей. Самым мощным фактором обеспечения нравственности бизнеса может быть эффективная экономическая политика правительства, защищающая национальные интересы страны и способствующая расцвету бизнеса. Цель такой политики - создать такой экономический уклад, который помог бы гармонично реализовывать духовные устремления и материальные интересы личности и общества, добиться того, чтобы интересы бизнеса и общества в целом совпадали. Этой гармонизации, как показывает исторический опыт, содействуют православные ценности и сформировавшиеся на их основе национальные традиции. Объединяющим начало государства и бизнеса являются национальные интересы многонационального народа России. Только в случае служения этим интересам отечественный бизнес сможет выполнить свою историческую миссию в новой России - стать экономическим локомотивом развития страны и обеспечения общественного блага.

Но для этого необходима разработка с одной стороны эффективных законодательных механизмов гарантий его стабильности и защищенности от фискальных структур, от несовершенства судебной системы. Должна быть разработана стимулирующая деловую активность кредитная политика. Необходимо законодательно стимулировать нравственно-ориентированный бизнес. Поступать безнравственно предпринимателю должно быть не выгодно. С другой стороны - поддерживать и пропагандировать добрые традиции, культивировать знание и понимание хода русской истории и развития культуры, придавать судебным делам максимальную гласность. Создать атмосферу убежденности в том, что богатство и власть дают не только права, но и накладывают на своего владельца серьезную ответственность перед обществом.

Перелома негативного хода истории во все времена удавалось добиться благодаря определенному социальному слою, сплоченному единством интересов и исторической судьбой. В обществе появлялось социальное ядро, способное увлечь за собой все другие слои населения. Таким ядром сейчас может стать предпринимательское сообщество, которое могло бы взять на себя миссию стать опорой нового подъёма страны. Для этого недостаточно единства интересов и типа деятельности. Нужно сознание внутреннего единства как духовно-нравственной целостности, как основы самоидентификации новой социальной силы в нашем обществе, способной взять на себя конструктивный ответ на вызовы нового столетия.

Эта социальная сила должна сохранить всё ценное из прошлых веков, научиться добиваться успеха в особенно конкурентном XXI веке, утвердить своё право жить достойно и сохранить свою неповторимость. Цель ее приложения должна иметь прямое отношение к обществу в целом, добиться его благополучия и общего всестороннего подъема страны на мировой арене - вот цель нравственного бизнеса в России.

\section{Литература}

Браим И. Этика делового общения. - Минск, 1996.

Инглегарт Р. Культурный сдвиг в зрелом индустриальном обществе // Новая индустриальная волна на Западе. Антология, Под редакцией В.Л. Иноземцева. - М.: Academia, 1999.
Тюленев А.И. Нравственный бизнес как проблема социологической науки и социальной практики. - Вестник экономики, права и социологии, 2015, №1.

Фукуяма Ф. Доверие: социальные добродетели и путь к процветанию: (пер. с англ.). - М.: АСТ Москва: Хранитель, 2006. 
ISSN 1508-7719

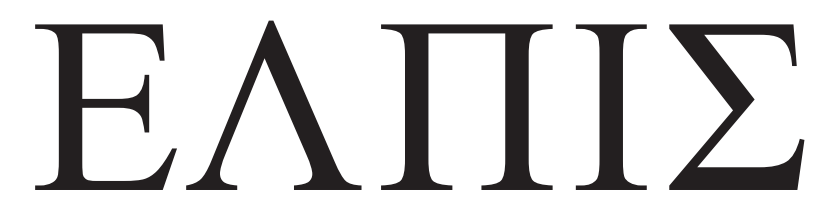

CZASOPISMO TEOLOGICZNE KATEDRY TEOLOGII PRAWOSŁAWNEJ UNIWERSYTETU W BIAŁYMSTOKU

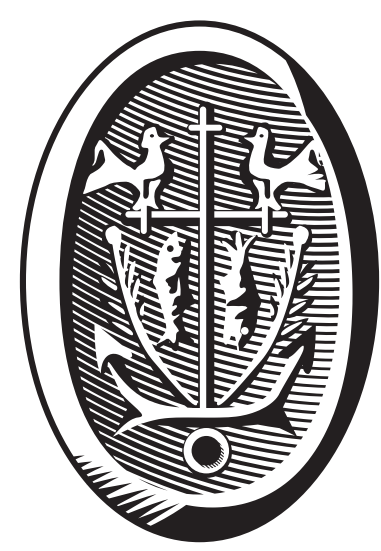

ADRES REDAKCJI

15-097 Białystok, ul. M. Skłodowskiej-Curie 14 tel. 85 745-77-80, e-mail: redakcja@elpis.edu.pl www.elpis.uwb.edu.pl 